\title{
Modelling water flow and seasonal soil moisture dynamics in an alluvial groundwater-fed wetland
}

\author{
I. Joris and J. Feyen \\ K.U.Leuven, Laboratory for Soil and Water Management, Vital Decosterstraat 102, 3000 Leuven, Belgium \\ Email for corresponding author: ingeborg.joris@agr.kuleuven.ac.be
}

\begin{abstract}
Complex interactions occur in riparian wetlands between groundwater, surface water and climatic conditions. Knowledge of the hydrology of these systems is necessary to understand their functioning and their value and models are a useful and probably essential tool to capture their hydrological complexity. In this study, a 2D-model describing saturated-unsaturated water flow is applied to a transect through a groundwaterfed riparian wetland located along the middle reach of the river Dijle. The transect has high levees close to the river and a depression further into the floodplain. Scaling factors are introduced to describe the variability of soil hydraulic properties along the transect. Preliminary model calculations for one year show a good agreement between model calculations and measurements and demonstrate the capability of the model to capture the internal groundwater dynamics. Seasonal variations in soil moisture are reproduced well by the model thus translating external hydrological boundary conditions to root zone conditions. The model proves to be a promising tool for assessing effects of changes in hydrological boundary conditions on vegetation type distribution and to gain more insight in the highly variable internal flow processes of riparian wetlands.
\end{abstract}

Keywords: riparian wetland, eco-hydrology, upward seepage, floodplain hydrology

\section{Introduction}

Wetlands depend on water, whether derived from precipitation, rivers, sea or groundwater. Therefore, to get insight in the functions they have, such as nutrient retention, flood mitigation, and the values they represent, such as their (often high) ecological value, knowledge of the hydrology of these systems is indispensable.

Riparian wetlands typically exhibit a high spatial and short-term variability resulting from the complex interplay of meteorological, hydrological and biological processes and the interactions with the surrounding terrestrial and aquatic systems (Dall'O' et al., 2001). To deal with the hydrological complexity of these systems and to make up water budgets and estimate fluxes, models are a useful and probably essential tool.

Previous modelling studies have followed diverse approaches with varying degrees of complexity. Groundwater flow models have been used to simulate water level variation in wetlands and estimate fluxes to and from the river with good results (Bradley, 1996; 2002; Burek and
Nestman, 2002; Mohrlok and Jirka, 2002), although lacking a description of processes such as capillary rise. A more complex model describing two-dimensional saturatedunsaturated flow was developed by Bates et al. (2000) to investigate hillslope, floodplain and channel interactions for a lowland river during over-bank floods. This model was further tested for in-bank floods (Burt et al., 2002). These studies were concerned mainly with floodplain-channel interactions and, although soil moisture was included in the latter model, the description of the atmospheric boundary was simplified and did not allow for soil-vegetation interactions. Dall'O' et al. (2001) followed a slightly different approach using a multi-box aggregation of processes to deal with the hydrological complexity of riparian zones and observed a good fit between observed and fitted water levels.

When focussing on eco-hydrological relations and the ecological value of riparian wetlands, a rather high degree of model complexity is in order. Eco-hydrology concentrates on linking hydrological processes to vegetation patterns and, 
to unify concepts from both hydrology and ecology, the notion of the site is introduced, i.e. the place providing the set of conditions in which a plant species or community lives. Causal relations can be made from external factors (e.g. parent material, catchment hydrology) and conditioning factors (e.g. soil texture, groundwater level) to operative site factors (e.g. water and nutrient availability) or root zone conditions (Klijn and Witte, 1999). Riparian wetlands experience varying degrees of saturation and, therefore, usually encounter periods where an unsaturated zone develops and the root zone is uncoupled from the groundwater table. Soil moisture then becomes a key to understanding root zone dynamics and must be included in the model concept together with a description of the climatesoil-vegetation interaction (Baird, 1999; Rodriguez-Iturbe, 2000).

In this study the saturated-unsaturated flow model HYDRUS-2D (Šimùnek et al., 1999) solving the Richards' equation is applied to a riparian wetland fed by upward groundwater seepage. The model is fully spatially distributed and takes soil moisture into account. The variability encountered in the soil hydraulic properties is approximated by a linear model using scaling factors. A description of atmospheric boundaries allows for two-way climate-soilvegetation interactions. The investigation explores: (1) whether the mechanistic model can serve as an operational tool to assess the effect of changes in external hydrological boundary conditions on vegetation-related groundwater parameters and (2) whether the model gives enough insight into the internal flow processes to clarify the causal chain that leads from external factors to spatially variable site factors within the wetland and provide a sound base to link hydrology to site ecology.

\section{Site description}

The study site is a riparian wetland in the nature reserve 'Doode Bemde', situated in the central part of Belgium, $8 \mathrm{~km}$ south of Leuven, in the middle course of the river Dijle. Here, the Dijle meanders with a valley approximately $1 \mathrm{~km}$ wide. Upward seepage of groundwater into the wetland has been established from piezometric data, vegetation data, regional groundwater modelling and temperature profiles (De Becker et al., 1999; Huybrechts et al., 2000; Joris and Feyen, 2002).

To quantify the upward flux, estimates from three of these methods were combined (Hunt et al., 1996). The regional groundwater flow model predicted an upward flux of 1-3 $\mathrm{mm} \mathrm{d}^{-1}$ at the site, while the measurements from two piezometers with different filter depths $182 \mathrm{~m}$ from the river gave a yearly average upward flux of $1.1 \mathrm{~mm} \mathrm{~d}^{-1}$. An inverse optimisation of the water velocity fitting measured temperature profiles resulted in a much higher value of $7 \mathrm{~mm} \mathrm{~d}^{-1}$ which was thought to be less reliable, since the value was so far from the others. Hence, based on the first two methods, a value of $1 \mathrm{~mm} \mathrm{~d}^{-1}$ was chosen as a reasonable estimate for the upward groundwater flux at the site.

The geological setting of the area can be summarised as a layer of alluvial silt and clay a few meteres thick over a shallow sandy aquifer (Formation of Brussels) underlain by a thick clay aquitard at approximately 10 metres depth (Formation of Ieper) (De Smedt, 1973; De Becker et al., 1999). During the formation of the floodplain, sedimentation of coarser particles occurred nearer the river whereas smaller particles travelled further from the river before settling down in a process of 'lateral fining' (Bierkens, 1994). This resulted in higher levees next to the river and floodplain depressions in the hinterland. In the floodplain section under study, there is a difference in height of $2 \mathrm{~m}$ between levee and floodplain depression. Together with the topographical gradient, a gradient in texture developed in the wetland from silt loam (levee) to silty clay (depression). In the alluvial sediments, two layers can be distinguished matching different periods of flooding. The lower and older layer contains no sand and has a more or less uniform distribution with distance from river, while the upper and younger layer contains also small amounts of coarser particles and displays this typical textural variation with distance to the river (De Smedt, 1973).

The floodplain depression has a minimum groundwater level of about $-40 \mathrm{~cm}$ below the surface and is inundated in winter. Overbank flooding of the river occurs only rarely, so the inundation water stems mainly from precipitation excess and upward seepage of groundwater. Some ditches drain the wetland but they are quite narrow and shallow and represent only a moderate amount of drainage. Unlike most floodplain depressions in the region, this wetland was not subject to medieval drainage works to make the land suitable for agricultural use and so it represents a fairly undisturbed system in equilibrium with the hydrological boundary conditions.

Around the floodplain depression, distinct zones of vegetation can be found with reed beds in the centre of the wetland, grading to tall-sedges and tall-herb fen, then to a fen meadow type and finally to a more terrestrial grassland type when reaching the river. Investigation of a larger 21 ha area containing the study site has proven the distribution of the different vegetation types to be most strongly linked to groundwater parameters such as mean level and amplitude (De Becker et al., 1999). Figure 1 shows the study site and a contour plot of the yearly average piezometric levels, which gives an indication of the main groundwater flow patterns. Groundwater flow is directed from the hillslopes 


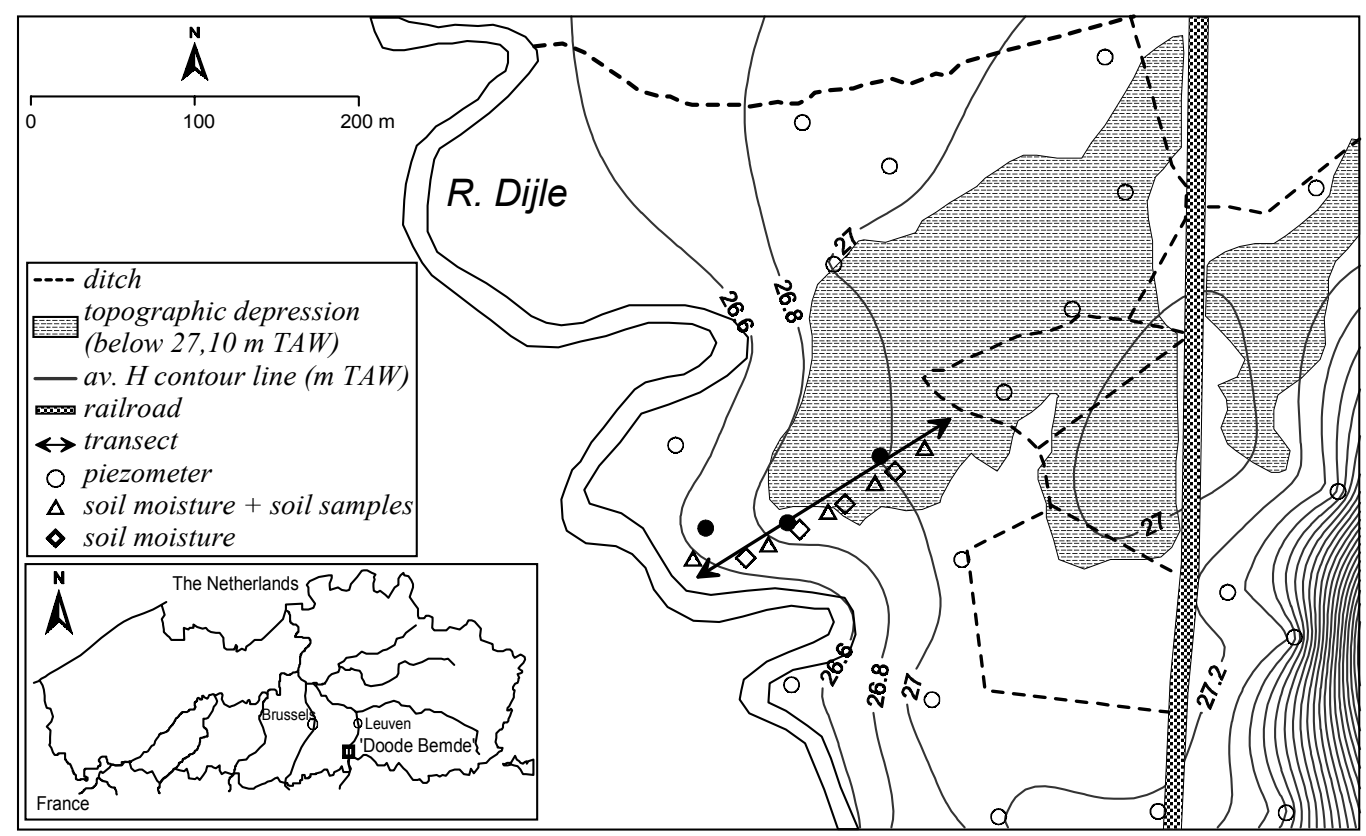

Fig. 1. Study site in Flanders (northern part of Belgium) and plan of the study site showing piezometer and sampling locations and contour lines of the average measured hydraulic head $H$, indicating main groundwater flow patterns.

(partly seen at the bottom right of the figure) towards the river, and is perpendicular to the river at the study site. The selected modelling domain is based on the transect in Fig. 1 crossing different vegetation zones, where groundwater flow can be considered mainly a two-dimensional process.

The levels in the piezometers are measured every fortnight and model calculations and measurements are compared for the three piezometers located on the transect. At nine different distances from the river, access tubes were installed for a TDR-probe to measure soil moisture content profiles every fortnight. Time Domain Reflectometry (TDR) is an indirect method to measure soil moisture content based on the difference in dielectric constant between soil, water and air and is widely applied in soil science (e.g. Topp et al., 1980; Heimovaara and Bouten, 1990). Since this research is concerned mainly with seasonal variations in water levels and water contents and with spatial variation along the transect, the time resolution of these measurements is considered to be satisfactory. At five different distances from the river, soil profile pits were dug and a total of 68 undisturbed soil cores (height $5,1 \mathrm{~cm}$, diameter $5 \mathrm{~cm}$ ) were taken at different depths for determination of soil hydraulic properties and root density. The saturated hydraulic conductivity was measured on these cores using the constant head method (Klute and Dirksen, 1986) and nine points of the retention curve were determined with a combination of hanging water columns and pressure cells (Klute, 1986).

\section{Model description}

\section{THEORY}

The HYDRUS-2D code numerically solves the Richards' equation for saturated-unsaturated water flow in two dimensions using Galerkin-type linear finite element schemes (Šimùnek et al., 1999). In a general form, the Richards' equation is given by:

$$
\frac{\partial \theta}{\partial t}=\nabla \cdot(K \nabla h+K \nabla z)-S
$$

where $\theta$ is the volumetric water content $\left[\mathrm{L}^{3} \mathrm{~L}^{-3}\right], t$ is time $[\mathrm{T}], \nabla$ a vector differential operator $\left[\mathrm{L}^{-1}\right], K$ the hydraulic conductivity $\left[\mathrm{L} \mathrm{T}^{-1}\right], h$ is pressure head $[\mathrm{L}], z$ is gravitational head [L], and $S$ a sink term accounting for root water uptake $\left[\mathrm{L}^{3} \mathrm{~L}^{-3} \mathrm{~T}^{-1}\right]$. K and $\mathrm{S}$ can be functions of position, $\theta$ or $h$, and time. The HYDRUS-2D model can handle non-uniform and anisotropic flow domains, delineated by irregular boundaries. The flow domain is represented by a finiteelement grid, where material properties such as hydraulic characteristics must be provided for each computational node and a degree of anisotropy must be assigned to each element in the flow domain.

The model can handle atmospheric boundary conditions given by values for rainfall and potential evapotranspiration fluxes at time intervals defined by the user. Given the relative root density in the modelling domain, the model calculates 
I. Joris and J. Feyen

the actual evapotranspiration flux taking into account the prevailing root zone soil moisture conditions.

\section{GRID DESIGN, BOUNDARY CONDITIONS AND INITIAL CONDITIONS}

The two-dimensional flow domain depicted in Fig. 2 ranges along the transect from the river to the small drainage ditch. In the vertical dimension, it stretches from the soil surface to the bottom of the alluvial silt layer where a transitional peat layer to the Brusselian sand starts. A finite-element grid covering this domain was constructed using the MESHGEN2D grid generator. The grid is constructed so that the nodal density is higher closer to the soil surface where more variable fluxes and larger gradients are expected. The positions of the filters of the piezometers were inserted beforehand in the grid to avoid interpolation errors when comparing model calculations with measurements. The selected grid consists of 20963 nodes and 39725 triangular elements.
In Table 1, an overview of the boundary conditions, their values and the data sources is given. The left and right boundaries of the flow domain are defined as specified head boundaries, where daily values of river stage are used for the left side and a winter ditch level and summer ditch level are used for the right boundary. The part of the left boundary extending higher than the maximum river water level is a no flux-boundary, whereas at the bottom the specified head distribution is extended to the bottom of the flow domain, lower than the river floor. This approach is also taken by Bates et al. (2000) and is argued to be physically more realistic than a no-flux boundary from the bottom of the river channel downwards, since the latter can lead to the development of spurious flow features.

The lower boundary of the domain is defined as a specified flux boundary, with a constant flux value of $1 \mathrm{~mm} \mathrm{~d}^{-1}$. The upper boundary of the flow domain follows the topography of the domain and consists of two parts: the highest part at the levee is defined as an atmospheric boundary whereas, for the boundary in the floodplain depression, two different

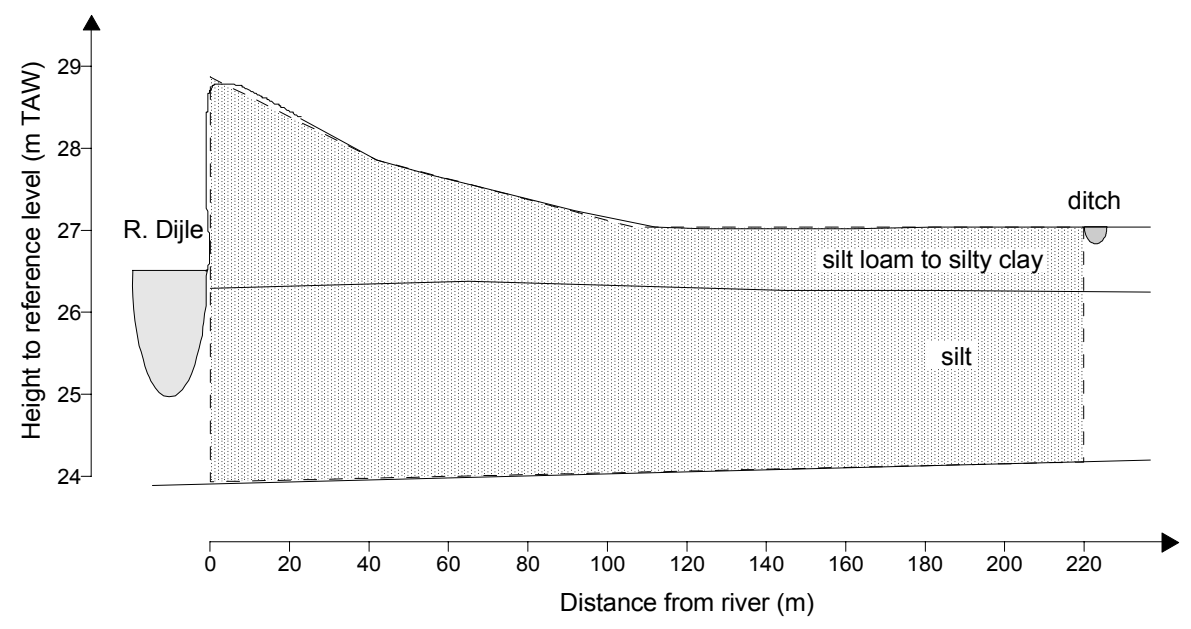

Fig. 2. View of the field situation and the two-dimensional flow domain.

Table 1. Definition and data sources for model boundary conditions

\begin{tabular}{|c|c|c|}
\hline Boundary & Specification & Value/Data source \\
\hline Upper boundary - levee & Atmospheric boundary & On site daily rainfall - Calculated $\mathrm{ET}_{0}$ \\
\hline \multirow[t]{2}{*}{ Upper boundary - depression } & Seepage face (winter) & - \\
\hline & Atmospheric boundary (summer) & On site daily rainfall - Calculated $\mathrm{ET}_{0}$ \\
\hline Left boundary & Specified head & $\begin{array}{l}\text { Daily river stage - hydrostatic equilibrium under maximum } \\
\text { level, no-flux above maximum level }\end{array}$ \\
\hline Right boundary & Specified head & Ditch - hydrostatic equilibrium with winter/summer level \\
\hline Lower boundary & Specified flux & Upward seepage flux $=1 \mathrm{~mm} \mathrm{~d}^{-1}$ \\
\hline
\end{tabular}




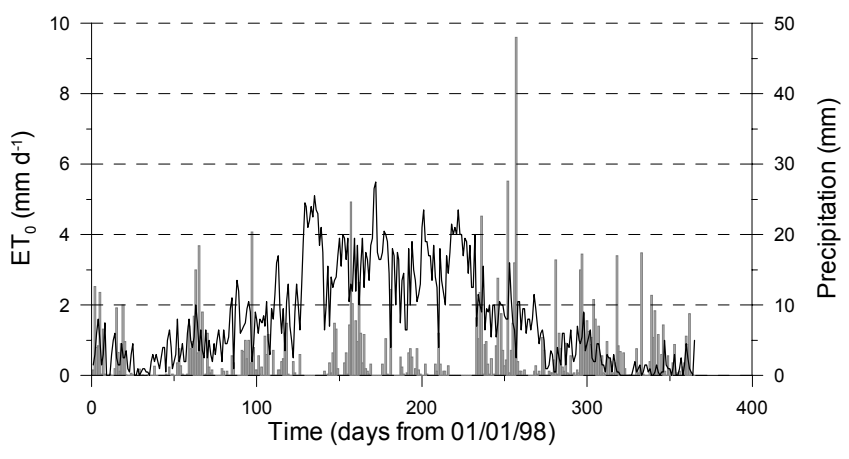

Fig. 3. Daily precipitation and $E T_{0}$-values for the simulation period.

types of boundary conditions are applied depending on the season. In winter, when the depression is inundated, the boundary in the floodplain depression is defined as a seepage face where water leaves the flow region when saturated. During the summer season, when the depression is flooded only for very short periods, the boundary is defined as an atmospheric boundary, with surface fluxes depending on precipitation and evapotranspiration. Daily rainfall values are measured on-site in a tipping bucket rain gauge, while potential $\mathrm{ET}_{0}$-values are calculated with the ETREF-program (Raes et al., 1986), using the modified Penman equation with coefficients adapted for Belgian conditions (Vázquez, 2003). The time series for meteorological conditions for the simulation period are depicted in Fig. 3.

For the initial pressure head distribution, hydrostatic equilibrium with the groundwater level at day 0 is assumed.

\section{SOIL HYDRAULIC PROPERTIES AND ROOTS}

In the model, the soil hydraulic properties are represented by the parameterisation given by van Genuchten (1980):

$$
\begin{aligned}
& \theta(h)=\left\{\begin{array}{cc}
\theta_{r}+\frac{\theta_{s}-\theta_{r}}{\sqrt{\left.1+(\alpha|h|)^{n}\right]^{m}}} & h<0 \\
\theta_{s} & h \geq 0
\end{array}\right. \\
& K(h)=K_{s} S_{e}^{0.5\left[1-\left(1-S_{e}^{1 / m}\right)^{m}\right]^{2}}
\end{aligned}
$$

where

$$
m=1-\frac{1}{n} ; \quad S_{e}=\frac{\theta-\theta_{r}}{\theta_{s}-\theta_{r}}
$$

with $\theta$ the volumetric water content $\left[\mathrm{L}^{3} \mathrm{~L}^{-3}\right], h$ pressure head $[\mathrm{L}], \theta_{r}$ residual water content $\left[\mathrm{L}^{3} \mathrm{~L}^{-3}\right], \theta_{s}$ saturated water content $\left[\mathrm{L}^{3} \mathrm{~L}^{-3}\right], \alpha$ air entry value $\left[\mathrm{L}^{-1}\right], K$ hydraulic conductivity $\left[\mathrm{L} \mathrm{T}^{-1}\right], K_{s}$ saturated hydraulic conductivity $[\mathrm{L}$ $\left.\mathrm{T}^{-1}\right], S_{e}$ effective water content and $m, n$ fitting parameters. The five independent van Genuchten parameters have to be provided for each node in the computational domain.

Analysis of the measured retention curves (as can be seen in Fig. 4 (a)) shows a distinct spatial variability in the top layer of the alluvium depending mainly on the distance to the river. To incorporate this heterogeneity into the model, a scaling approach is used. In such an approach, the assumption is made that the hydraulic variability in an area can be approximated by a set of linear scaling transformations which relate the individual soil hydraulic characteristics $\theta(\mathrm{h})$ and $\mathrm{K}(\mathrm{h})$ to reference characteristics $\theta^{*}\left(\mathrm{~h}^{*}\right)$ and $\mathrm{K}^{*}\left(\mathrm{~h}^{*}\right)$. Three scaling parameters $\alpha_{\mathrm{h}}, \alpha_{\theta}$ and $\alpha_{\mathrm{K}}$ are used to define a linear model of the actual spatial variability of the soil hydraulic properties as follows (Vogel et al., 1991):

$$
\begin{aligned}
& h=\alpha_{h} h^{*} \\
& \theta(h)=\theta_{r}+\alpha_{\theta}\left[\theta^{*}\left(h^{*}\right)-\theta_{r}^{*}\right\rfloor \\
& K(h)=\alpha_{K} K^{*}\left(h^{*}\right)
\end{aligned}
$$

In this study, a three step approach is followed to incorporate spatial variability expressed by scaling factors into the model. First, the van Genuchten parameters are fitted through the measured $\theta(\mathrm{h})$ points for each measuring location using the parameter estimation code RETC (van Genuchten et al., 1991). Then, the reference curve $\theta^{*}\left(\mathrm{~h}^{*}\right)$ and the scaling factors $\alpha_{\mathrm{h}}$ and $\alpha_{\theta}$ at each measuring location are calculated following the procedure outlined by Vogel $e t$ al. (1991). Finally, the scaling factors for each measuring location are expressed as a function of the distance from the river, since that appears to be the factor most strongly influencing the variation in hydraulic properties. These relations of $\alpha_{\mathrm{h}}$ and $\alpha_{\theta}$ as functions of distance to the river, in combination with the original relation $\alpha_{\mathrm{K}}=\alpha_{\mathrm{h}}^{-2}$ by Miller and Miller (1956) are incorporated into the model as an approximation to the real variability of soil hydraulic properties in the upper layer of the flow domain. Figure 4 (a) shows the original data for $\theta(\mathrm{h})$ with the least squares fit (which would be the resulting parameter set when assuming a homogeneous soil). The transformed data and the reference curve $\theta^{*}\left(\mathrm{~h}^{*}\right)$ are depicted in (b), and finally in (c), the actual curves resulting from the procedure are shown together with the original measurements. It is clear from Fig. 4 that describing the spatial variability of the hydraulic properties by incorporating scaling factors as a function of distance to the river, reduces the sum of squares of errors between measured and modelled $\theta(\mathrm{h})$ by a factor 2 from 1.50 to 0.75 . This validates the proposed procedure.

As an initial value for the reference saturated conductivity $\mathrm{K}_{\mathrm{s}}^{*}$, a value of $1.15 \mathrm{e}-5 \mathrm{~m} \mathrm{~s}^{-1}$, which is the arithmetic average of measured saturated conductivities, was used. Qualitative 
I. Joris and J. Feyen
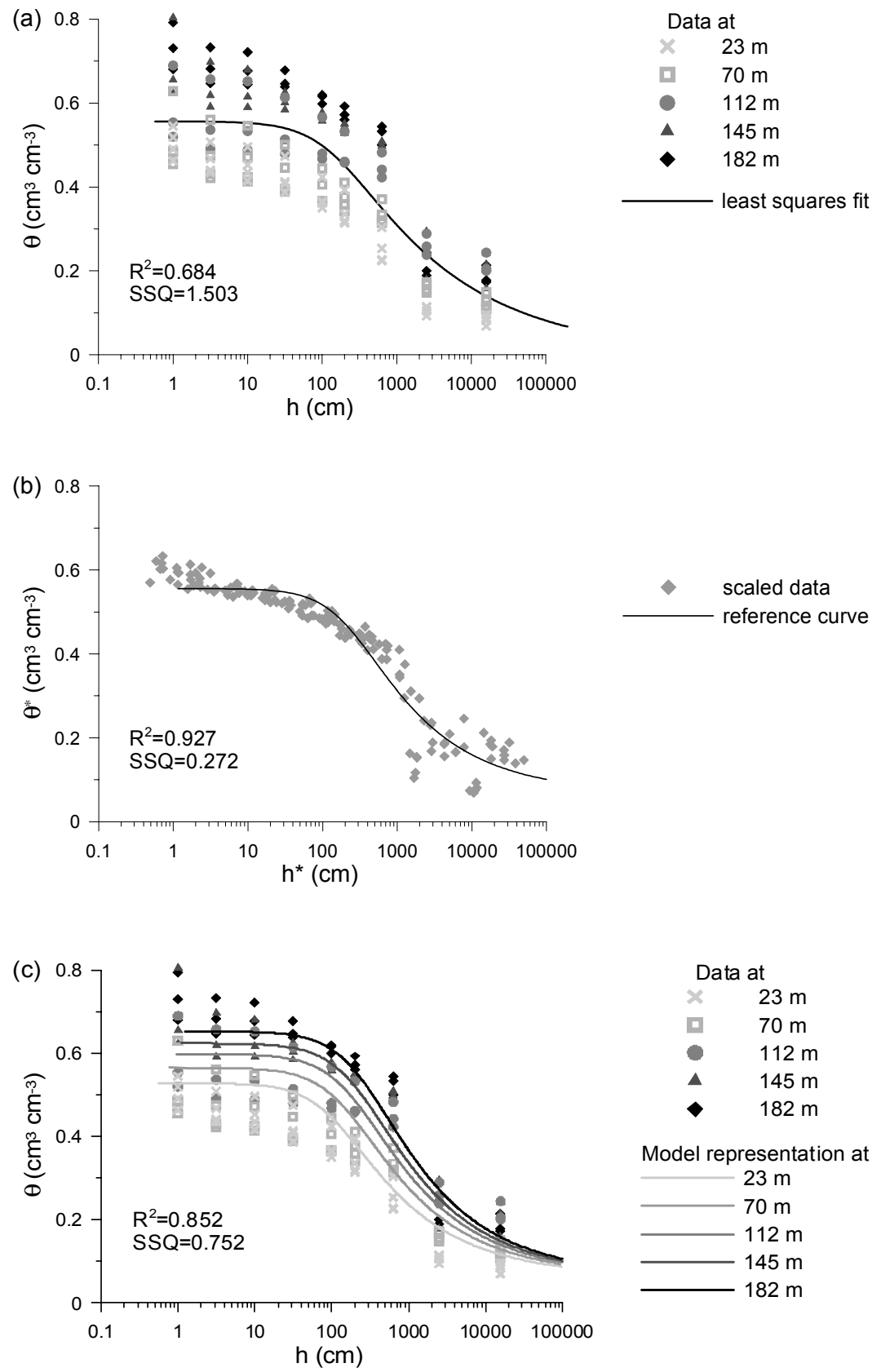

Fig. 4. Comparison of measured and fitted $p F$-data under the assumption of a homogeneous material (a), transformed data and reference curve applying the scaling procedure (b), and comparison between measured and fitted pF-data after the scaling procedure (c).

assessments of field boring tests led to the incorporation of an anisotropy factor of 10 , so that horizontal conductivity $\mathrm{K}_{\mathrm{H}}$ was 10 times the vertical conductivity $\mathrm{K}_{\mathrm{V}}$. Initial calculations showed that the calculated hydraulic heads were extremely sensitive to the value of $\mathrm{K}_{\mathrm{s}}^{*}$, and that the initial value was too high to predict the observed heads accurately. This parameter was then used as a calibration parameter for the winter period, and an optimal value of $9,84 \mathrm{e}-6 \mathrm{~m} \mathrm{~s}^{-1}$ was obtained.

The lower part of the alluvium shows much less variability and is assumed to be homogeneous silt, with hydraulic properties derived from the HYDRUS-2D model database. Table 2 gives an overview of the final sets of van Genuchten parameters for the reference curve in the upper layer and for the silt layer

Along the atmospheric part of the boundary, a relative root density distribution is reconstructed based on measured root densities. A linear distribution of roots with depth is assumed at each point, with two parameters, root zone depth and top root density determining root distribution. The root 
Table 2. Overview of the van Genuchten parameters for the reference curves of the top material ( $\mathrm{K}_{\mathrm{s}}^{*}$ after calibration) and for the lower silt layer

\begin{tabular}{llllll}
\hline & $\begin{array}{l}\theta_{\mathrm{s}} \\
\left(\mathrm{m}^{3} \mathrm{~m}^{-3}\right)\end{array}$ & $\begin{array}{l}\theta_{\mathrm{r}} \\
\left(\mathrm{m}^{3} \mathrm{~m}^{-3}\right)\end{array}$ & $\begin{array}{l}\alpha \\
\left(\mathrm{m}^{-1}\right)\end{array}$ & $\begin{array}{l}n \\
(-)\end{array}$ & $\begin{array}{l}K_{s} \\
\left(\mathrm{~m} \mathrm{~s}^{-1}\right)\end{array}$ \\
\hline Material 1 (reference curve) & 0.557 & 0.063 & 0.451 & 1.4357 & $9.838 \mathrm{e}-6$ \\
Material 2 & 0.460 & 0.034 & 1.600 & 1.3700 & $6.944 \mathrm{e}-7$ \\
\hline
\end{tabular}

zone depth is expressed as a linear function of distance to river with values between $30 \mathrm{~cm}$ in the depression and 90 $\mathrm{cm}$ close to the river. During winter, only the root zone in the levee is active and the top root density in the levee, $b_{1}$, was chosen to be 1 . In summer, the root zone of the whole transect is active and the top root density in the depression, $b_{d}$, was used as a calibration parameter. The best agreement between model calculations and observations of hydraulic head and soil moisture content was found for a value for $b_{d}$ of 0.8 .

\section{Results and discussion}

The model was run for 365 days starting on January 1st, 1998. Table 3 gives some statistical measures indicating the extent to which measurements and calculations agree. The rather high values indicate the model performs quite well in predicting both hydraulic heads and soil moisture content.

Figure 5 shows the resulting calculations of hydraulic head at the position of the three piezometers along the transect, together with the measurements at these points. As can be seen, the model performs quite well, especially in the wetter winter period at the beginning and the end of the year. The summer period consists of roughly two periods of drying out and rewetting of the soil. During the first of these two periods, the lowering of the water table is overestimated in the depression but is simulated fairly well closer to the river, although the shapes of the curves are slightly different for model and measurements. The second period is described quite well both in the depression and the levee and only the hydraulic heads are slightly underestimated closer to the river.

The data also show that the hydraulic gradient is directed mostly from the floodplain depression towards the river, with occasional short inversions. The direction of this gradient is predicted correctly by the model, which suggests that internal flow processes and their highly dynamical nature are represented well in the model structure developed.

Since the description of the porous medium lacks the level of detail to reproduce, accurately, point measurements of

Table 3. Different statistical measures for the goodness-of-fit between measured and calculated hydraulic heads $\mathrm{H}$ and measured and calculated soil moisture content $\theta$ (as defined in Legates and McCabe, 1999)

Statistical measure

Coefficient of determination $R^{2}\left(0 \leq R^{2} \leq 1\right)$

Coefficient of efficiency $E(-\infty \leq E \leq 1)$

Index of agreement $d(0 \leq d \leq 1)$

Relative Root Mean Square Error RRMSE

\section{Definition}

$$
R^{2}=\left\{\frac{\sum_{i=1}^{N}\left(O_{i}-\bar{O}\right)\left(P_{i}-\bar{P}\right)}{\left[\sum_{i=1}^{N}\left(O_{i}-\bar{O}\right)^{2}\right]^{0.5}\left[\sum_{i=1}^{N}\left(P_{i}-\bar{P}\right)^{2}\right]^{0.5}}\right\}^{2}
$$$$
E=1.0-\frac{\sum_{i=1}^{N}\left(O_{i}-P_{i}\right)^{2}}{\sum_{i=1}^{N}\left(O_{i}-\bar{O}\right)^{2}}
$$

$$
d=1.0-\frac{\sum_{i=1}^{N}\left(O_{i}-P_{i}\right)^{2}}{\sum_{i=1}^{N}\left(\left|P_{i}-\bar{O}\right|+\left|O_{i}-\bar{O}\right|^{2}\right.}
$$

RRMSE $=\frac{\sqrt{N^{-1} \sum_{i=1}^{N}\left(O_{i}-P_{i}\right)^{2}}}{\bar{O}}$

0.140 


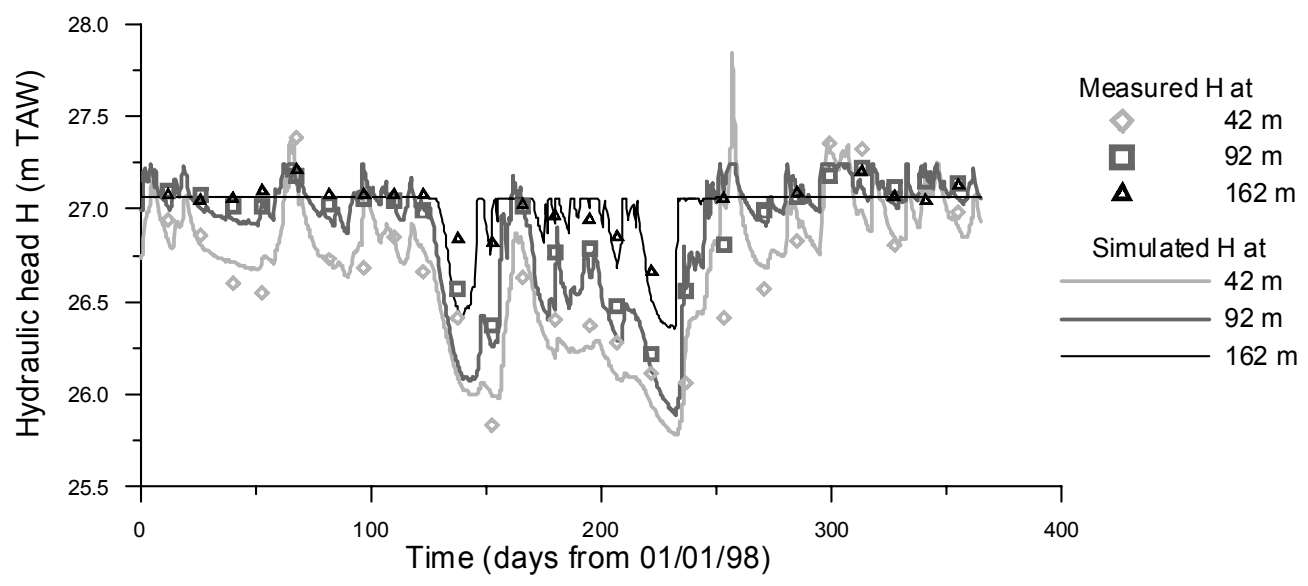

Fig. 5. Measured and simulated hydraulic heads at three different distances from the river.

soil moisture content at specific depths and the main interest of the modelling application was to reproduce seasonal soil moisture dynamics along the transect, average soil moisture contents were compared rather than individual observations. For each of the nine TDR measuring points, the soil moisture content for a soil profile of $0.5 \mathrm{~m}$ depth was calculated as a function of time by the model and compared to observed soil moisture contents averaged for the top $0.5 \mathrm{~m}$.

The model is quite capable of reproducing the seasonal dynamics of soil moisture content along the transect. Figure 6 , also shows that the periods of drying out are simulated well and that the transition from the groundwater-dominated depression to the atmospheric and river dominated levee is captured well. The description of the porous medium using scaling factors appears to be accurate enough to calculate soil moisture contents at different distances from the river. The performance of the model is less satisfactory closest to the river. Looking at the measured data in the three profiles at $70 \mathrm{~m}, 55 \mathrm{~m}$ and $23 \mathrm{~m}$ from the river, it can be seen that the lowering in soil moisture content in summer is the largest at $70 \mathrm{~m}$ and is less pronounced closer to the river, thus indicating that the atmospheric influence is largest at $70 \mathrm{~m}$ and is more and more compensated by interaction with the river when approaching the river. While this effect is reproduced by the model in the profiles at $70 \mathrm{~m}$ and $55 \mathrm{~m}$, the influence of the river at $23 \mathrm{~m}$ is far less dominant than that simulated by the model.

Overall, the model gives a fairly accurate description of the seasonal dynamics of groundwater and soil moisture along the transect and captures the dominant hydrological processes occurring, i.e. groundwater outflow with atmospheric interactions in summer for the depression and atmospheric interactions and river interactions for the levee. The model is able to link external hydrological boundary conditions to root zone conditions influencing vegetation directly and provides an important eco-hydrological link.

To use the model directly as a management tool, it should be able to reproduce the mean groundwater level and groundwater amplitude since distribution of different vegetation types is shown to be linked closely to these variables (De Becker et al., 1999). Figure 7 shows the modelling results together with the measured values. Two sets of model curves are given: the dotted lines are based on calculated groundwater levels for the 25 days when measurements were actually made and indicate model performance, while the full lines are based on 365 calculated daily groundwater levels (and represent the values one would get when measuring every day). The average groundwater level, as could be expected, is the same for the two types of model calculations, and agrees very well with the measured values. The model also gives a good prediction of the groundwater amplitude, although in the depression minimum and maximum levels are underestimated. Groundwater amplitudes calculated from the whole set of simulated groundwater levels are higher, especially in the levee. The transition from the atmospheric-river dominated levee to the groundwater-dominated depression is represented well by the model. Based on these results, the model seems to be a promising tool for evaluating the effect of changes in external boundary conditions, such as river level management, or groundwater extraction affecting upward seepage, on vegetation related groundwater parameters.

\section{Conclusions}

Introduction of scaling factors to describe the variation of soil hydraulic properties along the transect reduces the sum of squares of error between measured and modelled $\theta(h)$ by a factor of 2 , thus proving to be a valuable approach. Model 

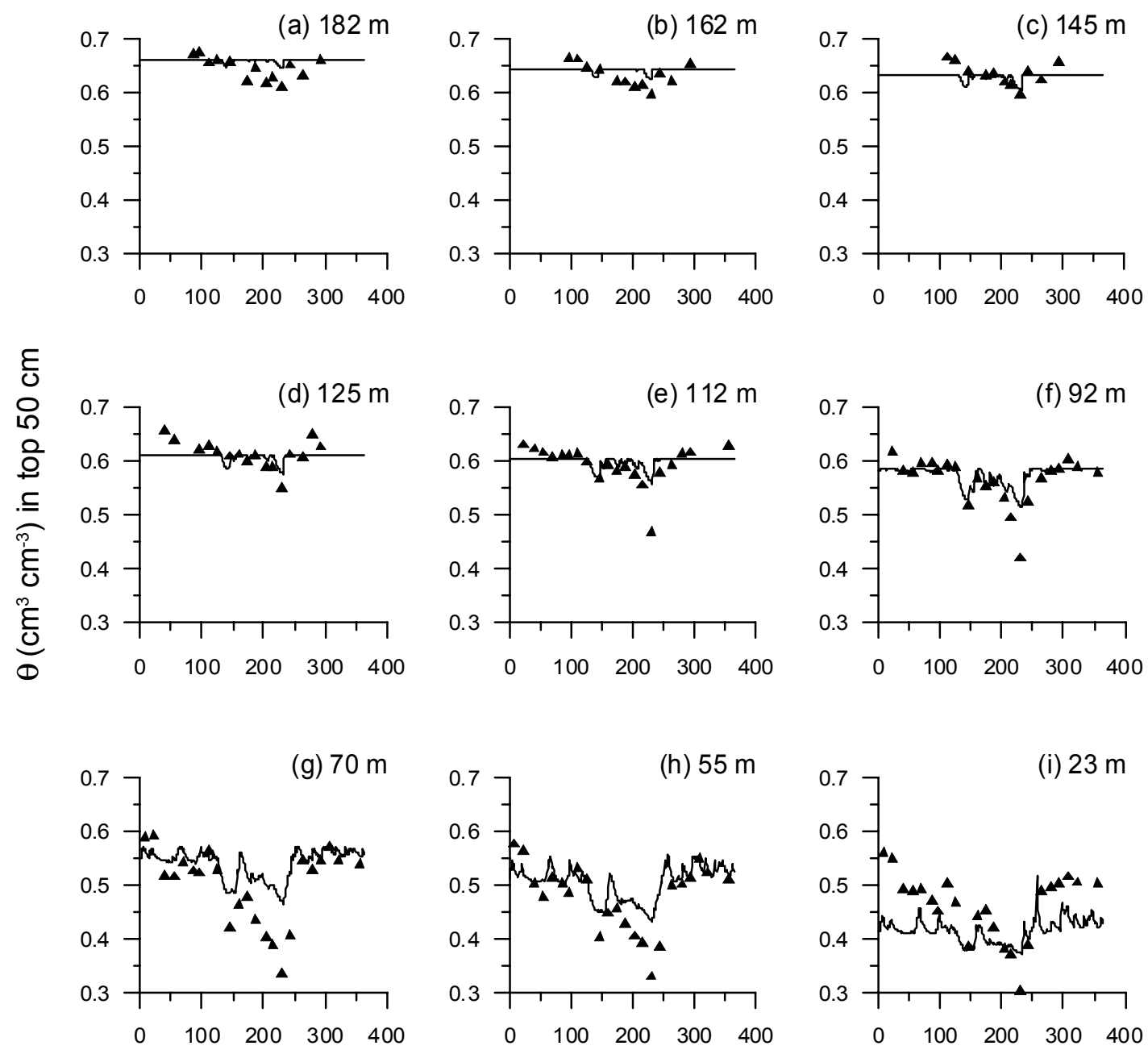

Time (days from 01/01/98)

Fig. 6. Measured and simulated soil moisture content of the top $50 \mathrm{~cm}$ of the soil at nine different distances from the river.

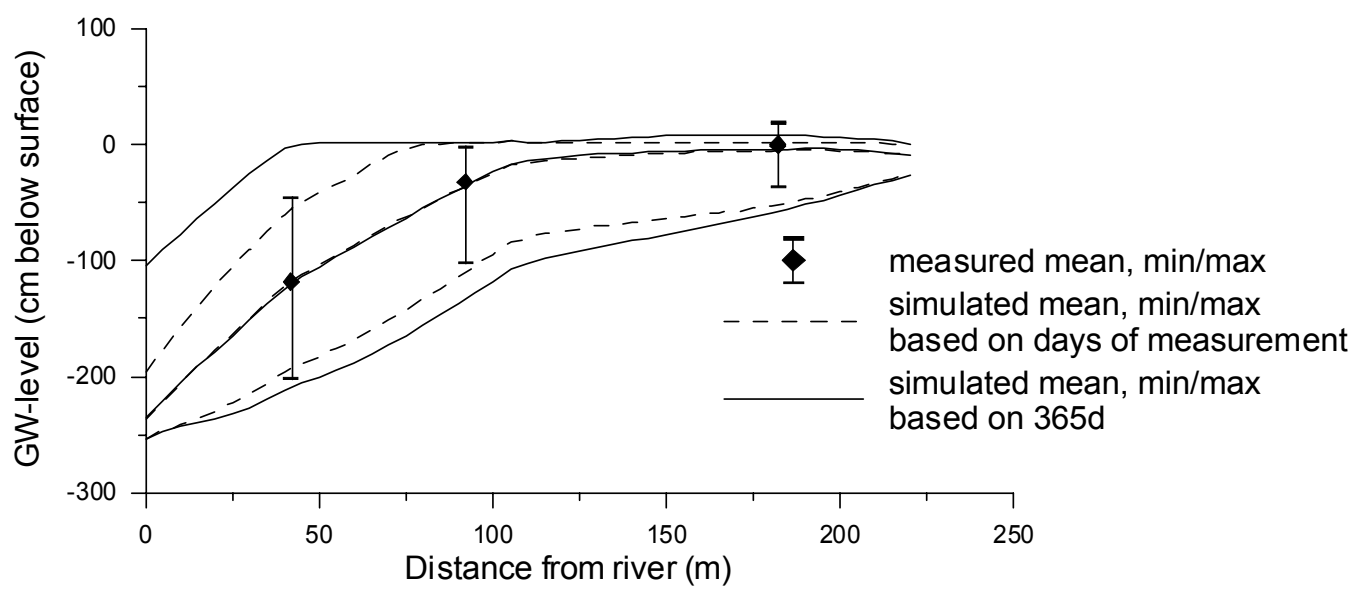

Fig. 7. Comparison between measured and simulated mean, minimum and maximum groundwater levels as functions of distance from the river. 
calculations of hydraulic head over a period of one year under atmospheric conditions agree fairly well with measurements and the dynamics of the hydraulic gradient are captured. The seasonal variation of soil moisture along the transect is reproduced quite well by the model although it overestimates the influence of river stage close to the river. The model is capable of describing the gradient in mean groundwater level and groundwater amplitude from river to floodplain depression and provides a promising tool for assessing the effect of changes in external hydrological boundary conditions on vegetation-related groundwater parameters.

\section{Acknowledgements}

The authors wish to thank the VLINA-program of the Flemish Community for the financial support through project C96/03 and the Institute for the Promotion of Innovation by Science and Technology in Flanders (IWT) for providing a scholarship.

\section{References}

Baird, A.J., 1999. Modelling. In: Eco-hydrology: plants and water in terrestrial and aquatic environments, A.J. Baird and R.L. Wilby (Eds.), Routledge, London. 300-345.

Bates, P.D., Stewart, M.D., Desitter, A., Anderson, M.G., Renaud, J.-P. and Smith, J., 2000. Numerical simulation of floodplain hydrology. Water Resour. Res., 36., 2517-2529.

Bierkens, M.F.P., 1994. Complex confining layers, a stochastic analysis of hydraulic properties at various scales. Ph.D. Dissertation, University of Utrecht, The Netherlands.

Bradley, C., 1996. Transient modelling of water-table variation in a floodplain wetland, Narborough Bog, Leicestershire. $J$. Hydrol., 185, 87-114.

Bradley, C., 2002. Simulation of the annual water table dynamics of a floodplain wetland, Narborough Bog, UK. J. Hydrology, 261, 150-172.

Burek, P. and Nestman, F., 2002. Auswirkung von Deichrückverlegungen auf die langfristige Grundwasserdynamik in Auen. In: Morphodynamik der Elbe, F. Nestmann and B. Büchele (Ed.), Institüt für Wasserwirtschaft un Kulturtechnik, Universität Karlsruhe (TH), Karlsruhe. 389-414.

Burt, T.P., Bates, P.D., Stewart, M.D., Claxton, A.J., Anderson, M.G. and Price, D.A., 2002. Water table fluctuations within the floodplain of the River Severn, England. J. Hydrol., 262, 1-20.

Dall'O', M., Kluge, W. and Bartels, F., 2001. FEUWAnet: a multibox water level and lateral exchange model for riparian wetlands. J. Hydrology, 250, 40-62.

De Becker, P., Hermy, M. and Butaye, J., 1999. Ecohydrological characterization of a groundwater-fed alluvial floodplain mire. App. Veg. Sci., 2, 215-228.

De Smedt, P., 1973. Paleogeografie en kwartair geologie van het confluentiegebied Dijle-Demer (in Dutch with English summary). Acta Geogr.Lovaniensia, 11, Leuven, Belgium. $141 \mathrm{pp}$.

Heimovaara, T.J. and Bouten, W., 1990. A computer controlled 36 channel time domain reflectometry system for monitoring soil water content. Wat. Resour. Res., 26, 2311-2316.
Hunt, R.J., Krabbenhoft, D.P. and Anderson, M.P., 1996. Groundwater inflow measurements in wetland systems. Wat. Resour. Res. 32, 495-507.

Huybrechts, W., Batelaan, O., De Becker, P., Joris, I. and van Rossum, P., 2000. Ecohydrologisch onderzoek waterrijke valleiecosystemen - VLINA96/03 (in Dutch). Institute for Nature Conservation, Brussels.

Joris, I. and Feyen, J., 2002. Using temperature profiles to estimate groundwater inflow/outflow in an alluvial wetland. In: Water quantity \& quality aspects in modeling and management of ecosystems, Proc. Third ICWRER Conf., 22-25 July 2002, Dresden (Germany). 163-168.

Klijn, F. and Witte, J.-P.M., 1999. Eco-hydrology: groundwater flow and site factors in plant ecology. Hydrogeol. J., 7, 65-77.

Klute, A., 1986. Water retention : laboratory methods. In: Methods of Soil Analysis, Part 1-Physical and Minerological Methods, Second Edition, A. Klute (Ed.). Agronomy, no. 9, Part 1, 2nd edition.

Klute, A. and Dirksen, C., 1986. Hydraulic conductivity and diffusivity : laboratory methods. In: Methods of Soil Analysis, Part 1-Physical and Minerological Methods, Second Edition, A. Klute (Ed.). Agronomy, no. 9, Part 1, 2nd edition.

Legates, D.R. and McCabe Jr., G.J., 1999. Evaluating the use of "goodness-of-fit" measures in hydrologic and hydroclimatic model validation. Water Resour. Res., 35, 233-241.

Miller, E.E. and Miller, R.D., 1956. Physical theory for capillary flow phenomena. J. Appl. Phys., 27, 324-332.

Mohrlok, U. and Jirka, G.H., 2002. Grundwasserdynamik in Vorland- und Auenbereichen am Beispiel des geplanten Deichrückverlegungsgebietes "Rogätz". In: Morphodynamik der Elbe, F. Nestmann and B. Büchele (Eds.), Institüt für Wasserwirtschaft un Kulturtechnik, Universität Karlsruhe (TH), Karlsruhe. 369-388.

Raes, D., Van Aelst, P. and Wyseure, G., 1986. ETREF, ETCROP, ETSPLIT and DEFICIT, a computer package for calculating crop water requirements, Reference manual. Laboratory for Soil and Water Engineering, K.U.Leuven, Leuven, Belgium.

Rodriguez-Iturbe, I., 2000. Ecohydrology: a hydrology perspective of climate-soil-vegetation dynamics. Water Resour. Res., 36, 3-9.

Šimúnek, J., Šejna, M. and van Genuchten, M.Th., 1999. The HYDRUS-2D software package for simulating water flow and solute transport in two-dimensional variably saturated media (version 2.0). U.S. Salinity Laboratory, Riverside, California.

Topp, G.C., Davis, J.L. and Anman, P.A., 1980. Electromagnetic determination of soil water content: measurement in coaxial transmission lines. Water Resour. Res., 16, 574-582.

van Genuchten, M.Th., 1980. A closed-form equation for predicting the hydraulic conductivity of unsaturated soils. Soil Sci. Soc. Amer. J., 44, 892-898.

van Genuchten, M.Th., Leij, F.J. and Yates, S.R., 1991. The RETC Code for Quantifying the Hydraulic Functions of Unsaturated Soils, Version 1.0. EPA Report 600/2-91/065. U.S. Salinity Laboratory, USDA, ARS, Riverside, California.

Vázquez, R., 2003. Effect of potential evapotranspiration estimates on effective parameters and performance of the MIKE SHEcode applied to a medium-size catchment. J. Hydrol., 270, 309 327.

Vogel, T., Cislerova, M. and Hopmans, J.W., 1991. Porous media with linearly variable hydraulic properties. Water Resour. Res., 27, 2735-2741. 